\author{
췌장 초음파 제대로 하기 \\ 이재준 ${ }^{*}$, 천영국 ${ }^{*}$ \\ ${ }^{1}$ 대구 이재준내과의원, ${ }^{2}$ 건국대학교 의과대학 내과학교실 소화기병센터
}

\title{
Correct Examination of Pancreas with Ultrasonography
}

\author{
Jae Joon Lee ${ }^{1^{*}}$, Young Koog Cheon ${ }^{2^{*}}$
}

${ }^{1}$ Lee Jae Joon Internal Medicine Clinic, Daegu; ${ }^{2}$ Digestive Disease Center, Department of Internal Medicine, Konkuk University School of Medicine,

Seoul, Korea

Well visualization of pancreas with ultrasonography is difficult due to its location and overlying stomach and bowel. For correct examination, patient visit clinic with overnight fasting or over 8 hours fasting state and avoid smoking or chewing gums. Most common interfering factor for examination of pancreas with ultrasonography is gas in stomach. To avoid interference with gas, we use some methods (compression, position change, water ingestion). Pancreas is not seen totally in one view. So transverse and longitudinal scan with obligue scan is recommended. Trans-splenic scan at left intercostal area is also useful for visualization of tail of pancreas. Vascular landmarks are also important for correct examination of pancreas. Pancreas ultrasonography can be used for detecting lesions, but pancreas can be poorly visualized due to all efforts. At then abdominal computed tomography or magnetic resonance imaging is recommended for better evaluation. At this article, we will discuss correct examination of pancreas with ultrasonography for better visualization.

Keywords: Pancreas; Ultrasonography; Gas; Correct examination

\section{서 론}

췌장은 후복막강에 위치하고 소화관이 앞쪽에 있어 초음파검 사가 쉽지 않다. 하지만 초음파 장비의 발달과 술기의 향상으로
제대로 관찰하면 췌장질환의 진단에 도움이 될 수 있다. 췌장 초음파검사의 목적은 췌장질환의 발견에 초점을 두고 있다. 하 지만 초음파검사에 병변이 안 보인다고 췌장에 이상이 없다고 하기는 어렵다. 임상 증상과 맞추어 필요하면 복부 전산화단층
Address for Correspondence: Jae Joon Lee, M.D.

Lee Jae Joon Internal Medicine Clinic, 14 Wolseo-ro, Dalseo-gu, Daegu 42780 , Korea

Tel: +82-53-626-7866, Fax: +82-53-626-7866

E-mail:drjlee13@naver.com

\section{Young Koog Cheon, M.D, Ph.D.}

Digestive Disease Center, Department of Internal Medicine, Konkuk University School of Medicine, 120-1 Neungdong-ro, Gwangjin-gu, Seoul 05030, Korea

Tel: +82-2-2030-7490, Fax: +82-2-2030-5029

E-mail: cyk@kuh.ac.kr / yksky001@hanmail.net

* These authors are co-corresponding authors.
Received : 2017.2. 23

Revised : 2017.3.20

Accepted: 2017.4. 7 
촬영이나 자기공명영상 등 다른 검사의 도움을 받아야 한다. 특 히 가스가 많아서 췌장을 충분히 관찰을 못하였거나 비만이 심 하여 초음파검사가 힘든 경우 복부 전산화단층촬영이 필요하다. 췌장 관찰에 방해인자로는 위장관 가스, 심한 비만, 수술창, 바 리움 조영술 등이 있으며 위장관 가스에 의한 방해는 압박법, 자 세변경, 음수법 등을 이용하여 어느 정도 해결이 가능하다[1,2]. 이런 여러 문제점들이 있지만 방사선의 해가 없어 임산부나 소아 에서 사용할 수 있는 장점도 있어 췌장 초음파검사를 제대로 하 는 방법을 안다면 진료에 큰 도움을 줄 수 있다고 생각한다. 본 논문에서는 췌장 초음파를 어떻게 하면 잘 할 수 있을까에 초점 을 맞추어 췌장의 해부, 스캔 방법, 췌장 관찰을 방해하는 요소 의 해결책 등에 대해 기술하고자 한다.

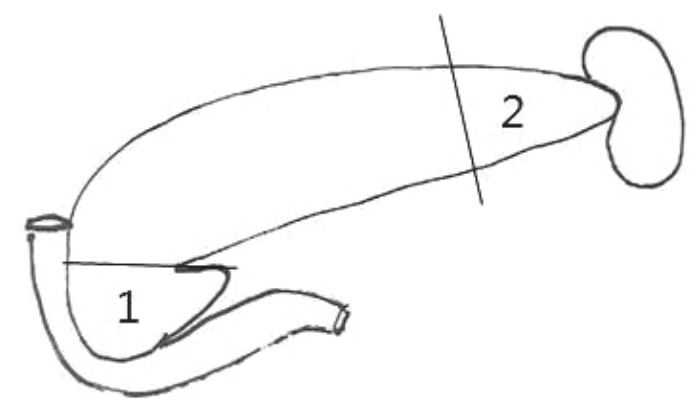

Figure 1. Blind point for scanning of pancreas. Tail and uncinate process of pancreas are difficult to scan with ultrasound imaging. 1, uncinate process; 2 , tail.

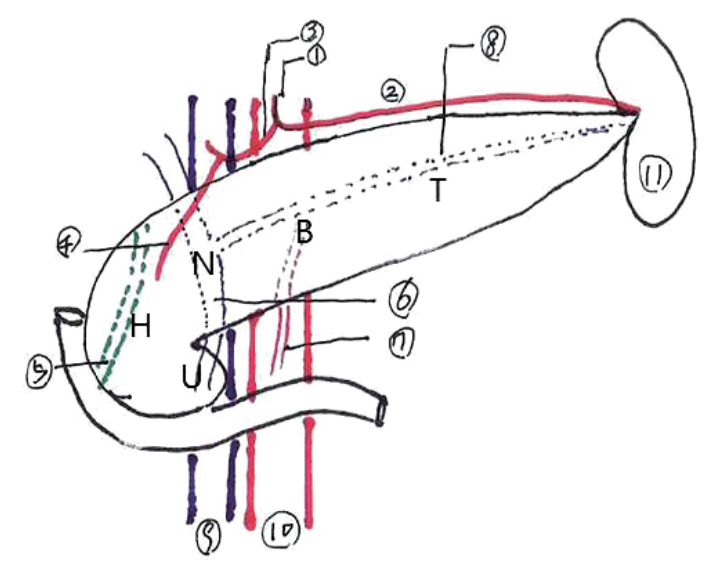

Figure 2. Peripancreatic vasculatures. (1), celiac artery; (2), splenic artery; (3), common hepatic artery; (4), gastroduodenal artery; (5), intrapancreatic common bile duct; (6), superior mesenteric vein; (7), superior mesenteric artery; (8), splenic vein; (9), inferior vena cava; (10, abdominal aorta; (11), spleen; $H$, head of pancreas; $N$, neck of pancreas; $U$, uncinate process of pancreas; $B$, body of pancreas; $T$, tail of pancreas.

\section{본 론}

\section{췌장의 해부 및 주위 혈관}

췌장은 후복막강 장기로서 전방에 소화관이 있고 후방에는 비 정맥이 주행하고 두부는 십이지장과 접하고 미부는 비장에 접한 다. 췌장은 두부, 경부, 체부, 미부, 구상돌기로 나누며 미부와 구 상돌기의 관찰이 어렵다(Fig. 1). 췌장 주위의 혈관들은 췌장을 찾는데 중요한 지표들이므로 잘 알고 있어야 하겠다(Fig. 2). 횡 단 스캔상 초음파의 해부를 보면 두부는 상장간막정맥의 우측 에, 경부는 상장간막정맥의 전방에, 구상돌기는 상장간막정맥의 후방에 있으며 체부는 비정맥의 전방에 있고 미부는 복부 대동 맥의 좌측에서 비장 사이에 위치한다(Fig. 3) [3,4].

\section{췌장의 스캔 방법}

췌장의 스캔 방법으로는 (1) 횡단 스캔, (2) 종단 스캔, (3) 사행
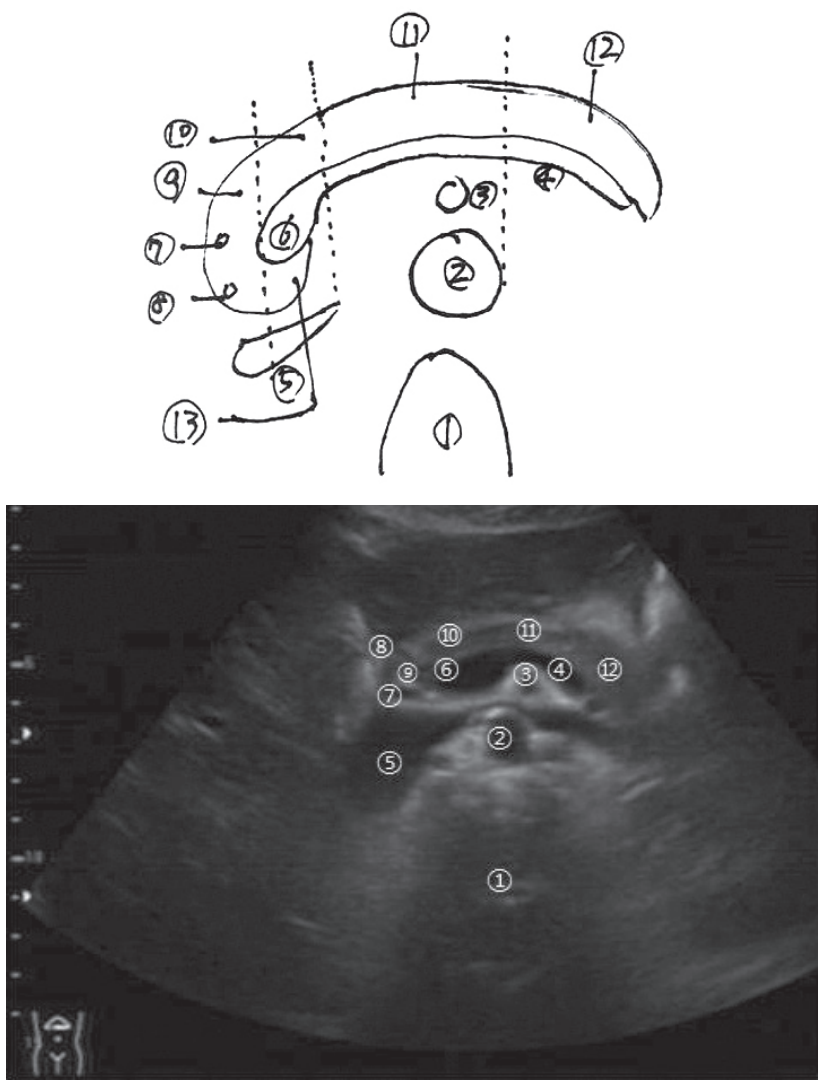

Figure 3. Anatomy of pancreas and surrounding vessels at ultrasound image. (1), vertebra; (2), abdominal aorta; (3), superior mesenteric artery; (4), splenic vein; (5), inferior vena cava; (6), superior mesenteric vein; (7), gastroduodenal artery; (8), intrapancreatic common bile duct; (9), head of pancreas; (10), neck of pancreas; (11), body of pancreas; (12), tail of pancreas; (13), uncinate process of pancreas. 
스캔, (4) 좌늑간-경비장 스캔, (5) 우하측와위 좌늑골하 횡단 또 는 사행 스캔이 있다[2,4].

\section{횡단 스캔}

탐촉자를 심와부에서 상하로 움직이면서 관찰한다.

\section{복강동맥 레벨}

탐촉자를 심와부에서 비스듬히 기울였다가 세우면서 관찰하 면 맨 먼저 대동맥에서 분지되는 복강동맥과 복강동맥에서 분지 되는 총간동맥과 비동맥을 관찰할 수 있다(Fig. 4).

\section{비정맥-상장간막동맥 레벨}

탐촉자를 복강동맥 레벨 위치에서 조금 더 세우면 복부대동 맥 위에 상장간막동맥이 보이고 그 위에 호상의 비정맥이 보이 고 비정맥 위에 췌장이 보인다. 췌장 두부에는 2개의 작은 원형 구조물이 보이는데 위쪽이 위-십이지장동맥이고 아래쪽이 췌장 내 총담관이다(Fig. 5).

\section{상장간막정맥 레벨}

탐촉자를 비정맥-상장간막동맥 레벨 위치에서 조금 더 내리
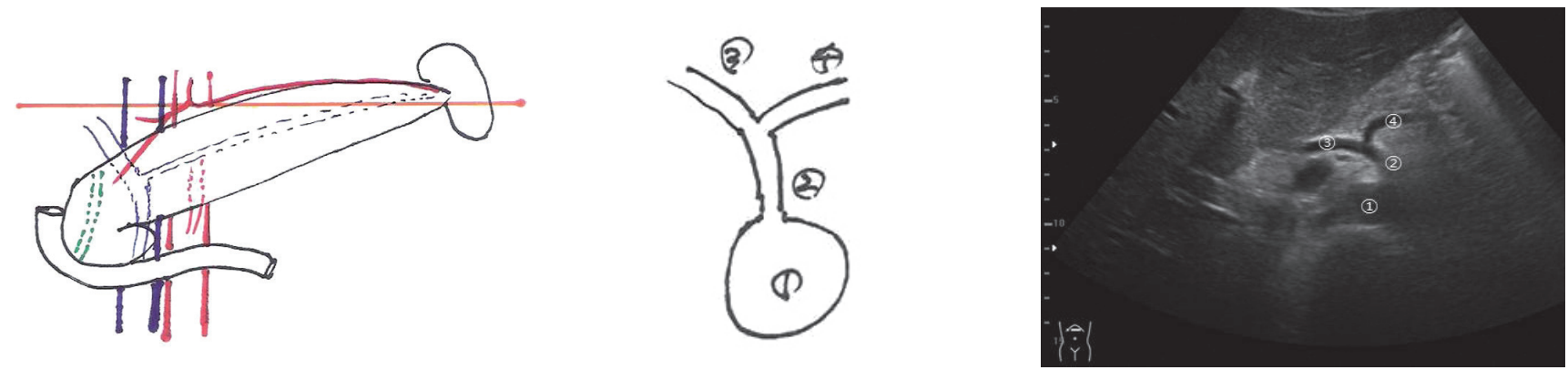

Figure 4. Transverse scan at celiac artery level. (1), abdominal aorta; (2), celiac artery; (3), common hepatic artery; (4), splenic artery.
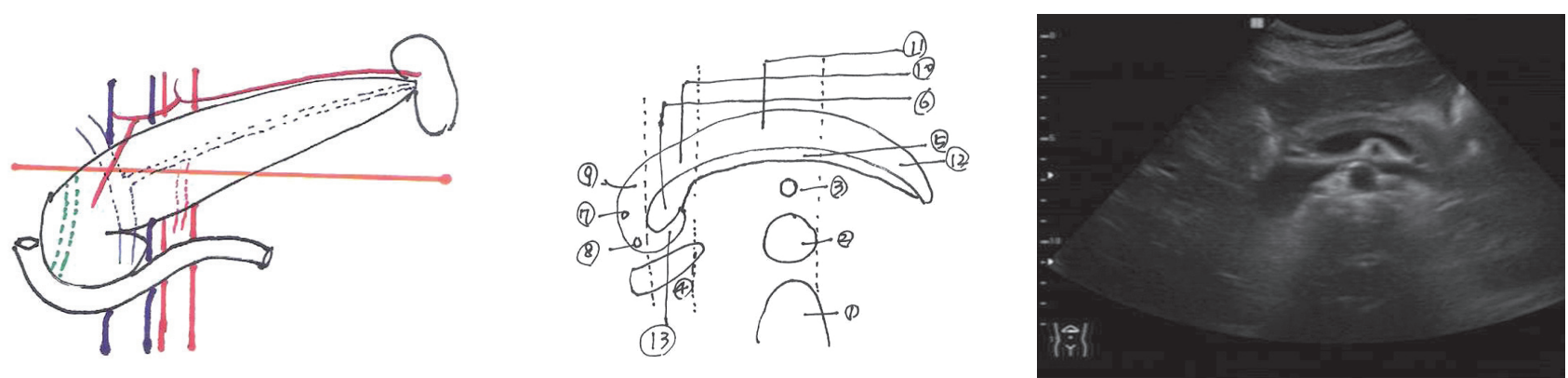

Figure 5. Transverse scan at splenic vein- superior mesenteric artery level. Transverse scan at splenic vein-superior mesenteric artery level shows abdominal aorta at mid-portion. Above abdominal aorta superior mesenteric artery is seen and above superior mesenteric artery round splenic vein is seen. Above splenic vein we can see body, neck, a portion of head and tail of pancreas. (1), vertebra; (2), abdominal aorta; (3), superior mesenteric artery; (4), inferior vena cava; (5), splenic vein; (6), superior mesenteric vein; (7), gastroduodenal artery; 8, intrapancreatic common bile duct; (9), head of pancreas; (10), neck of pancreas; (11), body of pancreas; (12), tail of pancreas; (13), uncinate process of pancreas.
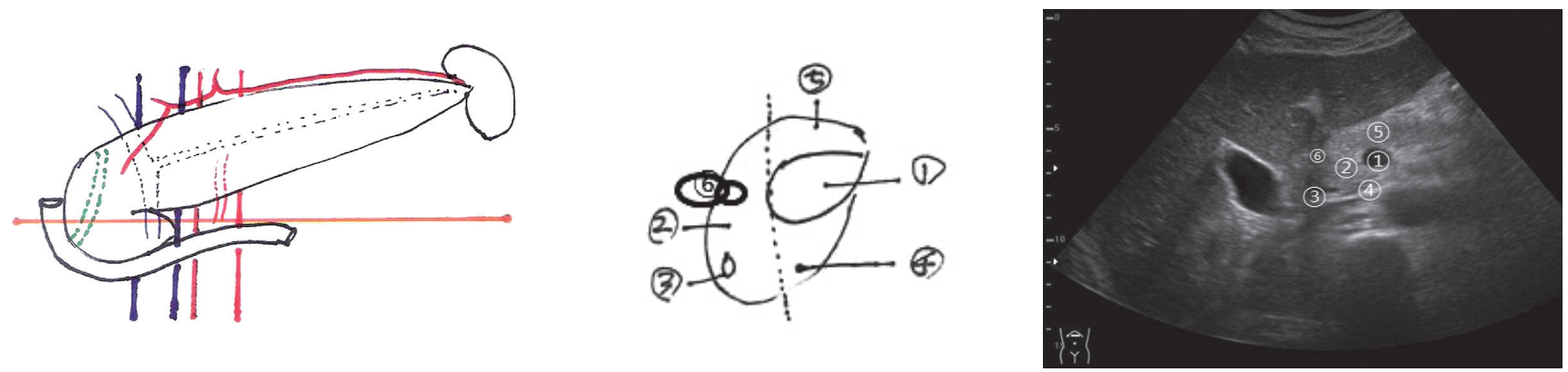

Figure 6. Transverse scan at superior mesenteric vein level. Transverse scan at superior mesenteric vein level shows oval superior mesenteric vein and neck, head and uncinate process are seen around superior mesenteric vein. (1), superior mesenteric vein; (2), head of pancreas; (3), intrapancreatic common bile duct; (4), uncinate process of pancreas; (5), neck of pancreas; (6), gastro-duodenal artery. 
면 비정맥은 잘 보이지 않고 상장간막정맥이 보이고 상장간막정 맥을 둘러싸고 있는 구상돌기, 췌장 두부, 췌장 경부가 잘 보인 다(Fig. 6).

\section{종단 스캔}

탐촉자를 횡단 스캔에서 90 도 시계방향으로 돌려서 심와부에 서 우측으로 이동하며 관찰한다.

\section{대동맥-상장간막동맥 레벨}

심와부에서 종단 스캔하면 대동맥에서 분지되는 상장간막동
맥과 복강동맥이 보이고 상장간막동맥 위에 타원형의 비정맥이 보이고 그 위쪽에 췌장 체부가 보인다(Fig. 7).

\section{간문맥 레벨}

심와부에서 탐촉자를 우측으로 이동하면 간문맥이 보이고 간 문맥 위쪽에 췌장 경부, 아래쪽에 구상돌기가 보인다(Fig. 8).

\section{하대정맥 레벨}

간문맥 레벨 위치에서 탐촉자를 좀 더 우측으로 이동하면 하 대정맥 위에 타원형의 췌장 두부가 보이고 췌장 두부 앞에 간문 맥이 보인다. 췌장내 총담관이 보이기도 한다(Fig. 9).
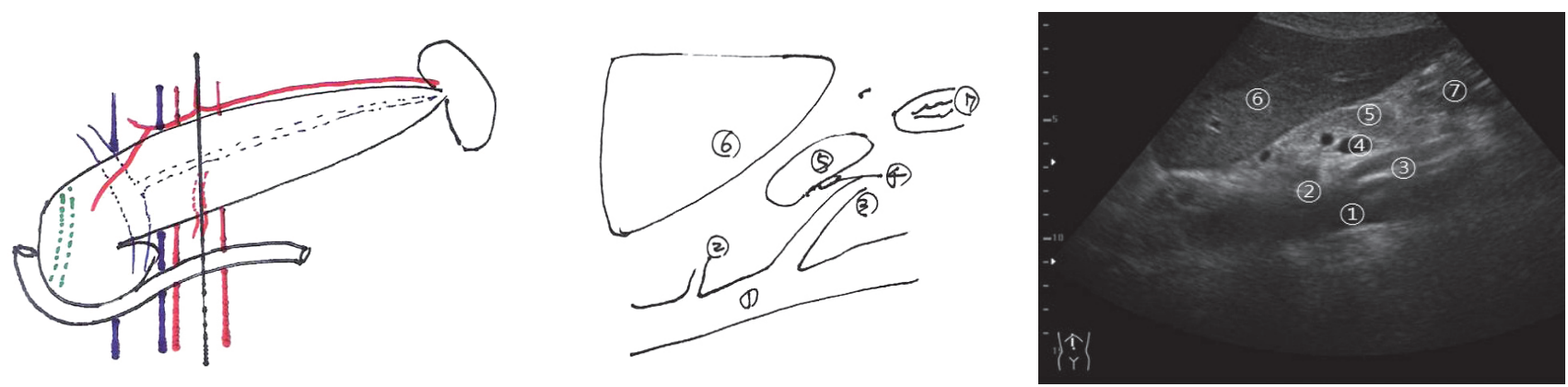

Figure 7. Longitudinal scan at aorta-superior mesenteric artery level. Longitudinal scan at epigastric area shows abdominal aorta and superior mesenteric artery. Above superior mesenteric artery body of pancreas is seen. (1), abdominal aorta; (2), celiac artery; (3), superior mesenteric artery; (4), splenic vein; (5), body of pancreas; (6), left lobe of liver; (7), stomach.
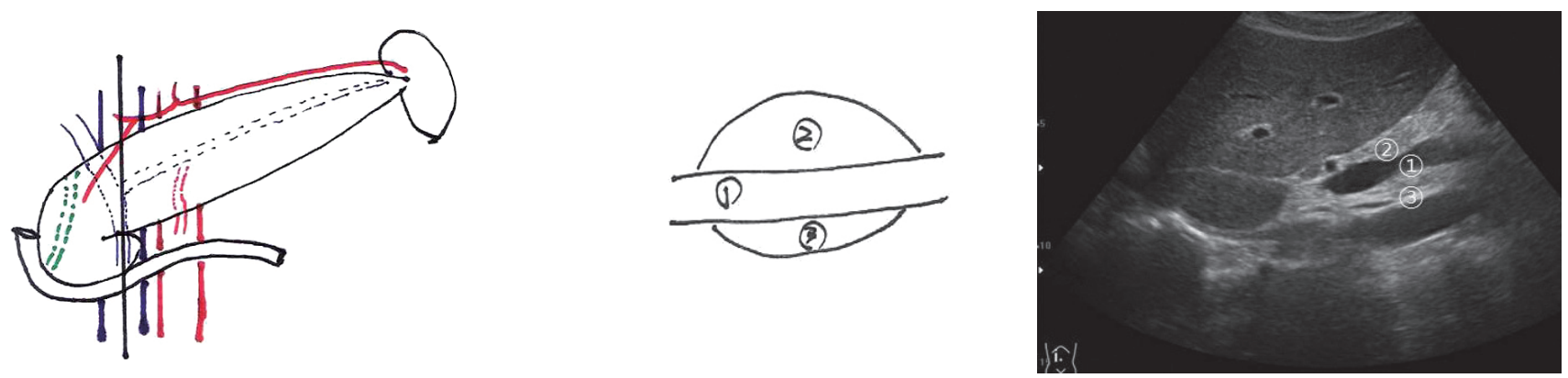

Figure 8. Longitudinal scan at portal vein level. Scanner move to right side from epigastrium. Longitudinal scan at there shows hypoechoic bar suggest portal vein. Above portal vein neck of pancreas is seen. Uncinate process of pancreas is seen below portal vein. (1), portal vein; (2), neck of pancreas; (3), uncinate process of pancreas.
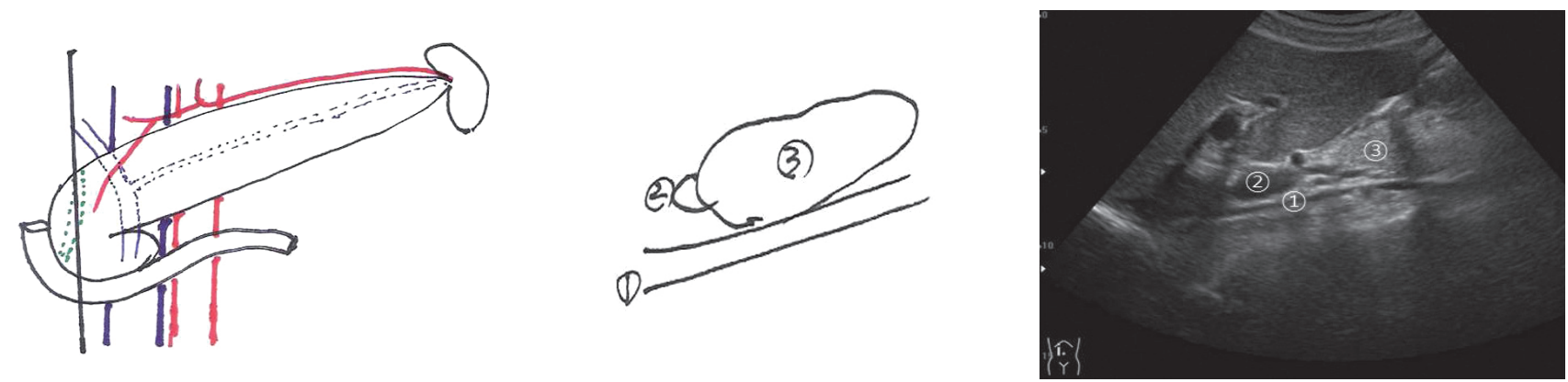

Figure 9. Longitudinal scan at inferior vena cava level. Longitudinal scan at inferior vena cava level shows pancreas head above inferior vena cava. (1), inferior vena cava; (2), portal vein; (3), head of pancreas. 


\section{사행 스캔}

심와부 횡단 스캔에서 탐촉자를 시계 반대방향으로 20도 정도 돌리면 횡단 스캔보다 췌장 미부가 더 잘 보일 수 있다(Fig. 10).

증례: 17세 여자가 복통, 소화불량을 주소로 내원하여 초음파 검사를 하였다. 심와부 횡단 스캔에서는 췌장 미부에 경계가 불 확실한 저에코 병변이 의심되었다(Fig. 11). 사행 스캔에서는 췌 장 미부의 저에코 병변이 더 뚜렷하게 관찰되었다(Fig. 11).

\section{죄늑간-경비장 스캔}

좌늑간에서 비장을 음향창으로 관찰하면 비정맥 위로 췌장 미부를 관찰할 수 있다(Fig. 12).

\section{우하측와위 좌늑골하 횡단 또는 사행 스캔}

피검자를 우측으로 눕힌 후 좌늑골하에서 횡단 또는 사행 스 캔을 하면서 등쪽을 다른 손으로 압박하면 비정맥과 그 위쪽의 췌장 미부를 잘 관찰할 수 있다(Fig. 13).

\section{췌장 스캔시 방해되는 인자들 및 해결책}

\section{췌장 스캔시 방해되는 인자들}

위장관내 가스, 심한 비만, 수술 창, 바리움 조영술(위, 대장) 등이 있다[2].
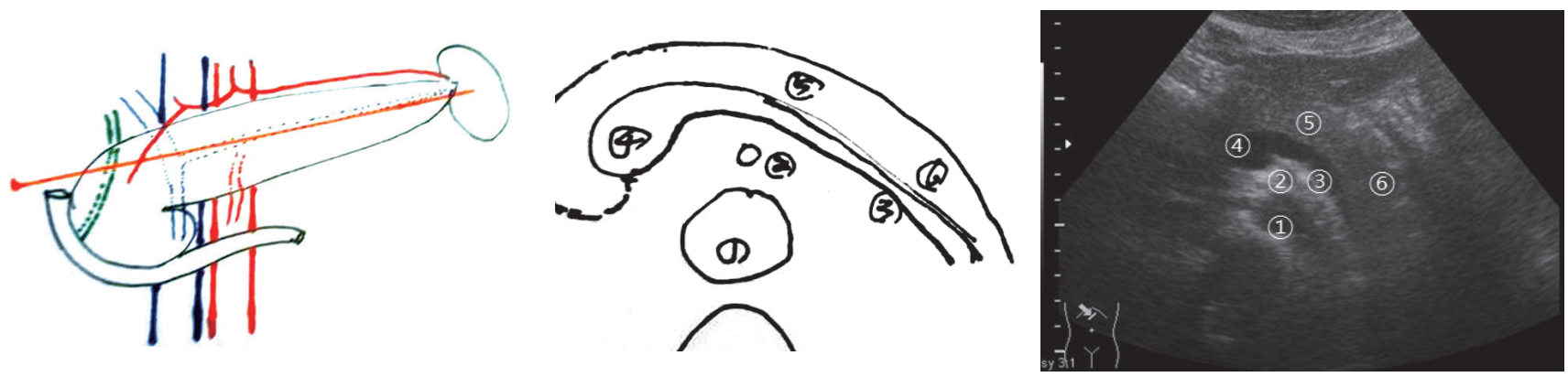

Figure 10. Oblique scan at epigastric area. Oblique scan at epigastric area (probe would be rotated 20 degree countclockwisely from transverse scan) shows tail of pancreas much better than transverse scan. (1), abdominal aorta; (2), superior mesenteric artery; (3), splenic vein; (4), superior mesenteric vein; (5), body of pancreas; (6), tail of pancreas.
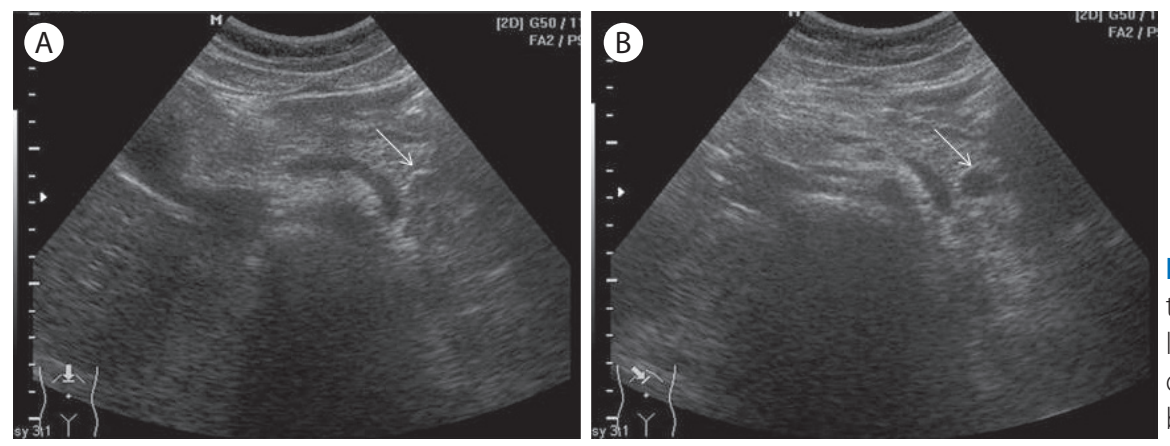

Figure 11. Cystic lesion at tail of pancreas. On transverse scan, poorly visualized hypoechoic lesion (arrow) is found at tail of pancreas (A) but on oblique scan, hypoechoic lesion (arrow) is better visualized than transverse scan (B).
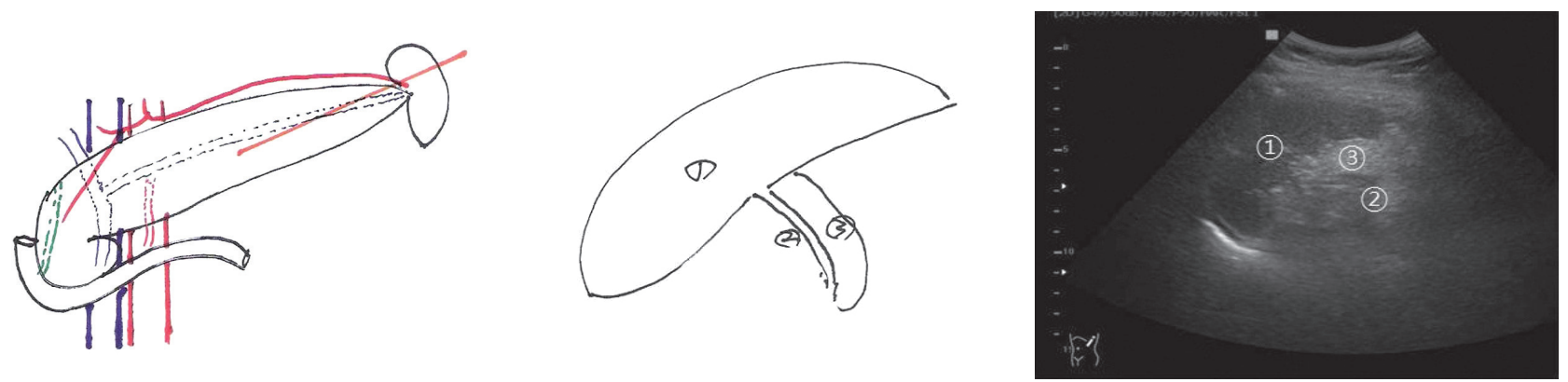

Figure 12. Left intercostal scan (trans-splenic approach) of pancreas. With trans-splenic approach at left intercostal scan, tail of pancreas is better visualized above splenic vein. (1), spleen; (2), splenic vein; (3), tail of pancreas. 

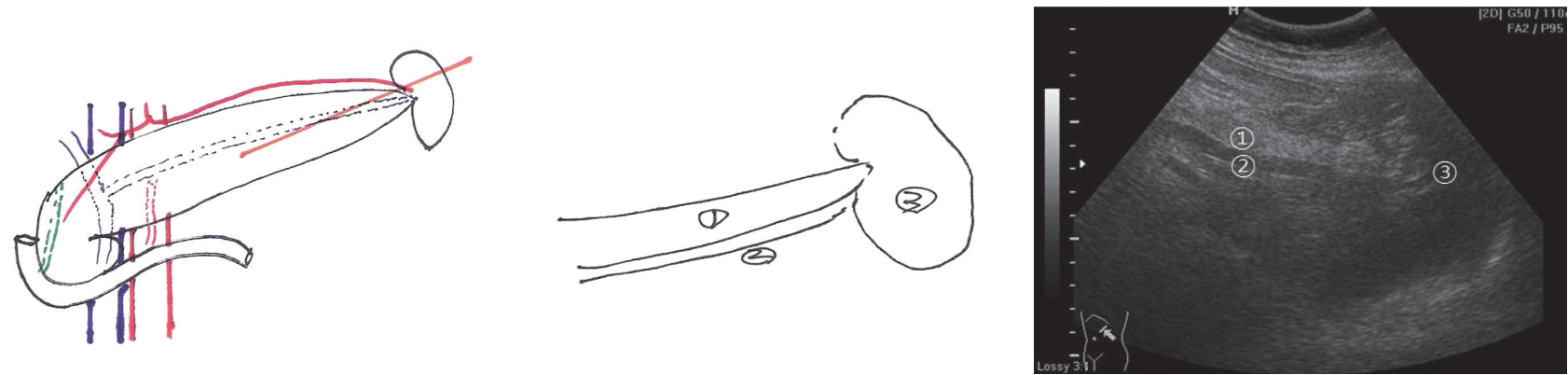

Figure 13. Left subcostal transverse or oblique scan with right lateral decubitus position. Left subcostal transverse or oblique scan with right lateral decubitus position also shows tail of pancreas better than transverse scan. (1), tail of pancreas; (2), splenic vein; (3), spleen.
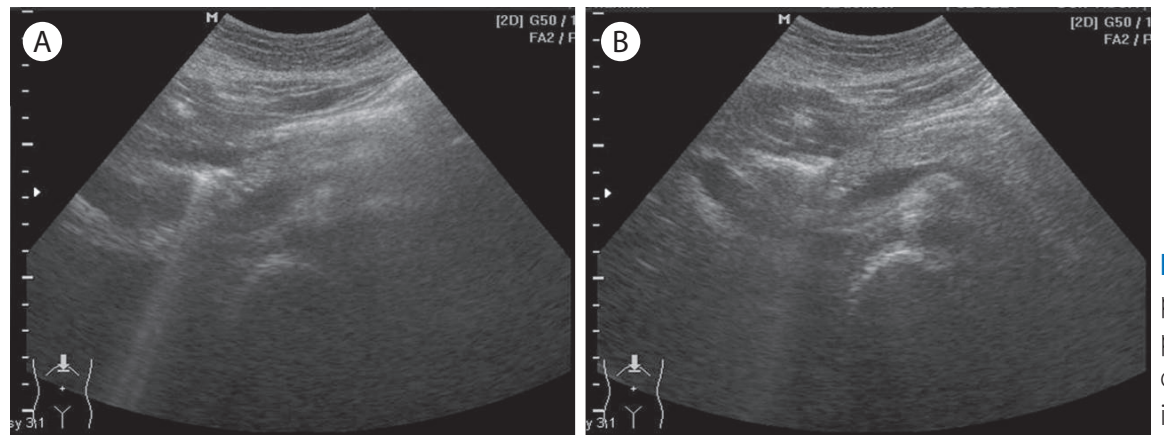

Figure 14. Before and after compression for pancreas scan. Before compression, pancreas is poorly visualized due to stomach gas (A). After compression, pancreas is well visualized than image before compression (B).
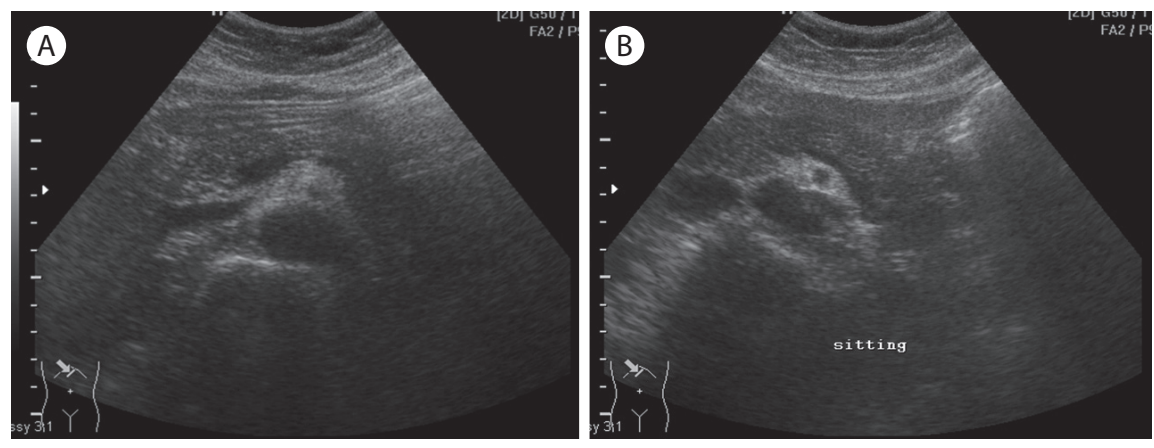

Figure 15. Before and after position change for pancreas scan. Before position change (supine position) tail of pancreas is poorly visualized (A) but after position change (sitting position) pancreas is well visualized than previous image (B).

\section{위장관내 가스가 많을 때 해결책}

\section{압박법}

위에 가스가 많아서 췌장이 잘 안보일 때(Fig. 14A) 탐촉자로 복부를 점진적으로 압박하여 위의 가스를 밀어내면 췌장이 더 잘 보인다(Fig. 14B).

\section{자세 변경}

누워서 췌장 스캔시 췌장이 잘 안보이면(Fig. 15A) 반좌위 또 는 좌위로 스캔하면 췌장이 더 잘 보인다(Fig. 15B).

\section{음수법[5]}

압박법 및 자세 변경의 방법을 사용해도 췌장이 잘 안보이면
(Fig. 16A) 위에 300-500 mL의 물을 먹이고 5 내지 10분 정도 앉 힌 후 검사하면 췌장이 더 잘 보이는 경우가 많다(Fig. 16B). 하 지만 이런 모든 방법을 동원해도 췌장이 잘 보이지 않으면 복부 전산화단층촬영 등 다른 검사의 도움을 받는 것이 좋다.

\section{췌장 제대로 스캔하기}

한 화면에서 췌장 전체를 볼 수 없으므로 두부, 체부, 미부, 경 부 및 구상돌기로 나누어서 검사하는 것이 좋다.

\section{췌장 체부}

심와부 횡단 스캔과 종단 스캔으로 관찰하고 누워서 잘 안보 이면 앉혀서 관찰하거나 위에 물을 먹인 후 관찰하면 더 잘 보인 

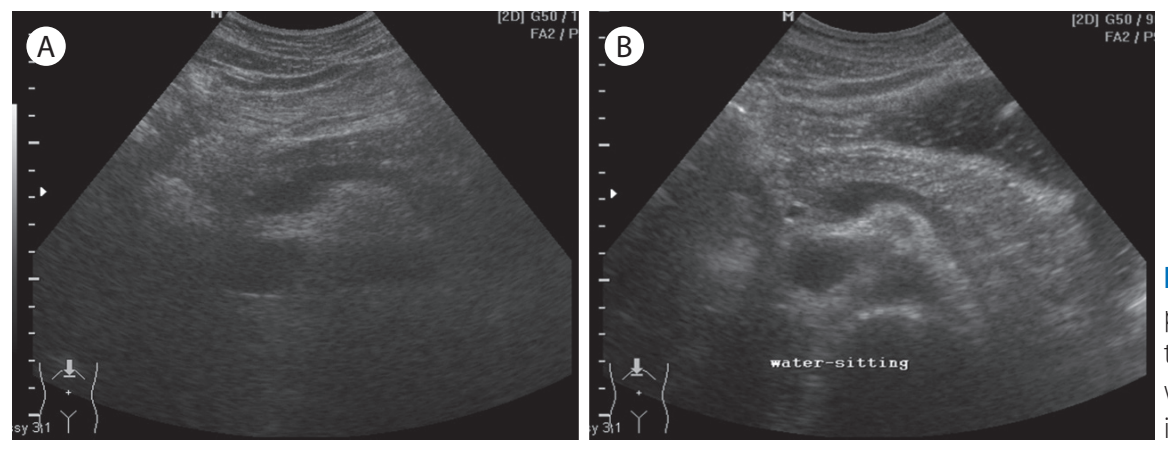

Figure 16. Before and after water ingestion for pancreas scan. Before water ingestion, body and tail of pancreas is poorly visualized (A) but after water ingestion, pancreas is well visualized than image before water ingestion (B).
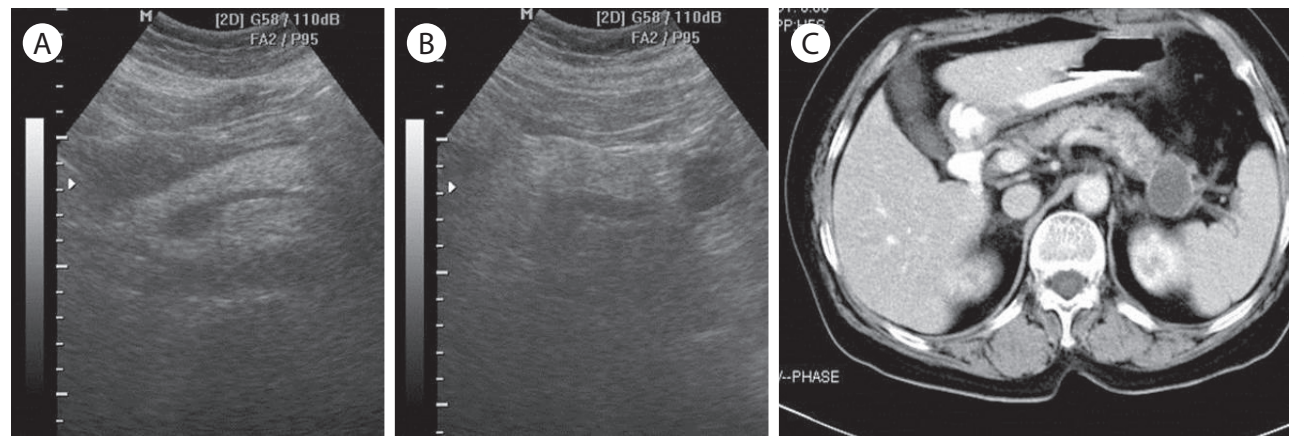

Figure 17. Hypoechoic lesion at tail of pancreas. At transverse scan, tail of pancreas is not seen due to gas (A) but at left subcostal scan with right lateral decubitus position hypoechoic mass is seen at tail of pancreas (B). On CT scan, hypoechoic mass at tail of pancreas suggest benign tumor (C). Five years later malignant intraductal papillary mucinous neoplasm (IPMN) is suggested on ultrasonographic examination. CT, computed tomography.
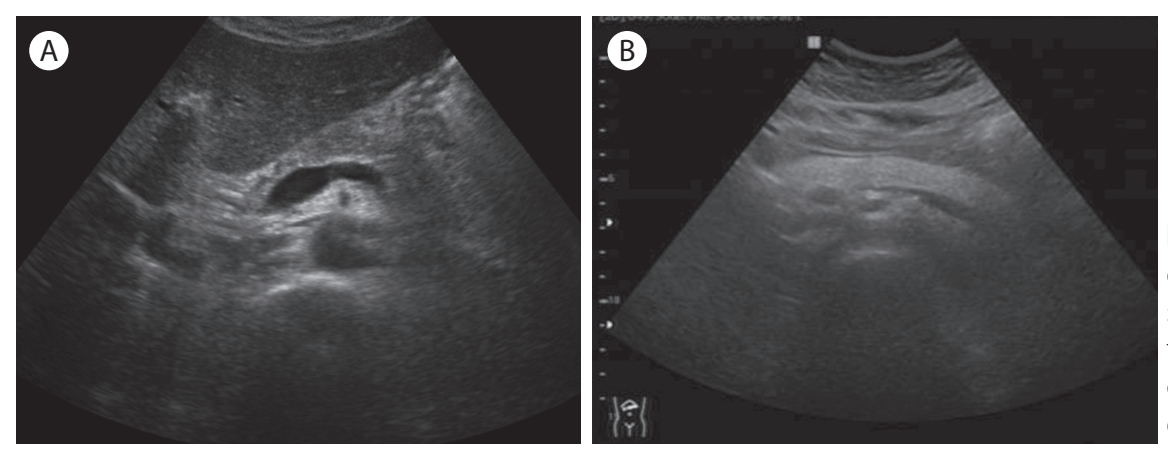

Figure 18. Echo texture of pancreas. Normal echo texture of pancreas is similar to liver or slightly hyperechoic than liver but hypoechoic than renal sinus (A). Hyperechoic texture of pancreas is seen in diabetes mellitus, old age and obesity (B).

다. 췌장 체부 관찰의 해부학적 지표는 대동맥-상장간막동맥-비 정맥이다. 심와부에서 탐촉자를 비스듬히 기울인 상태에서 세우 면서 관찰하면 대동맥 위에 상장간막동맥이 보이고 그 위에 호 상의 비정맥이 보이며 비정맥 위에 췌장 체부가 보인다(Fig. 5). 심와부 종단 스캔에서도 대동맥에서 분지되는 상장간막동맥을 찾으면 그 이에 타원형의 비정맥이 보이고 비정맥 위쪽에 췌장 체부가 보인다(Fig. 7).

\section{췌장 두부}

심와부 횡단 스캔에서 상장간막정맥 우측에서 보이며 췌장 두 부에 2개의 작은 원형 구조물이 관찰되는데 위쪽이 위-십이지장 동맥 아래쪽이 췌장내 총담관이다(Figs. 5 and 6). 심와부 종단 스캔에서 탐촉자를 우측으로 이동하여 하대정맥 레벨에서 스캔
하면 타원형의 췌장 두부가 잘 보인다(Fig. 9).

\section{췌장 경부 및 구상돌기}

심와부 횡단 스캔에서 췌장 체부의 우측, 상장간막정맥의 위쪽 에 췌장 경부가 보이고 상장간막정맥 아래쪽에 상장간막정맥을 싸고 도는 구상돌기가 보인다(Fig. 5). 구상돌기를 더 잘 보기 위 해서 탐촉자를 약간 아래로 내려 비정맥이 잘 안보이고 상장간 막정맥만 보이도록 하면 구상돌기가 더 잘 보인다(Fig. 6). 심와 부 종단 스캔에서 탐촉자를 이동하여 간문맥을 길게 관찰하면 간문맥 위쪽에 췌장 경부, 아래쪽에 구상돌기가 보인다(Fig. 8).

\section{췌장 미부}

심와부 횡단 스캔에서는 췌장 미부의 일부만 보이므로 췌장 미부를 잘 보기 위해서는 탐촉자를 시계 반대방향으로 20도 정 


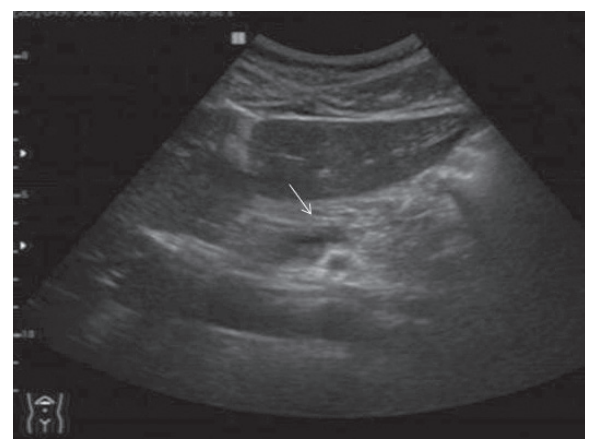

Figure 19. Normal pancreatic duct. Normal pancreatic duct is seen at body of pancreas. Its size is below $2 \mathrm{~mm}$. At old age, pancreatic duct can be dilated without disease.

도 돌려서 스캔하거나(Fig. 10) 좌늑간-경비장 스캔으로 비장을 음향창으로 관찰하거나(Fig. 12) 우하측와위 좌늑골하 횡단 또 는 사행 스캔을 하면 췌장 미부가 좀 더 잘 보이는 경우가 많다 (Fig. 13).

증례: 63세 여자가 복통, 소화불량을 주소로 초음파검사를 하 였다. 심와부 횡단 스캔에서 췌장 미부가 보이지 않았으나 우하 측와위 좌늑골하 횡단 스캔에서 췌장 미부에 저에코 종괴가 발 견되었고 복부 전산화단층촬영에서 양성 종양이 의심된다고 하 였다(Fig. 17).

\section{정상 췌장의 초음파상}

췌장 스캔시 췌장 실질의 에코, 췌장의 크기, 췌관의 확장 유 무, 종양의 유무 등을 관찰한다.

\section{췌장 실질의 에코}

췌장 실질의 에코는 간 실질과 비슷하거나 약간 높고 신동보다 는 낮다(Fig. 18A). 고령이나 심한 비만에서는 췌장 실질이 고에 코로 보일 수 있다(Fig. 18B).

\section{췌관의 직경}

정상 췌관의 직경은 $2 \mathrm{~mm}$ 를 넘지 않는다(Fig. 19).

\section{췌장의 크기}

정상 췌장의 크기는 두부 $2.5 \mathrm{~cm}$, 체부 및 미부 $2 \mathrm{~cm}$ 정도이다 (Fig. 20).

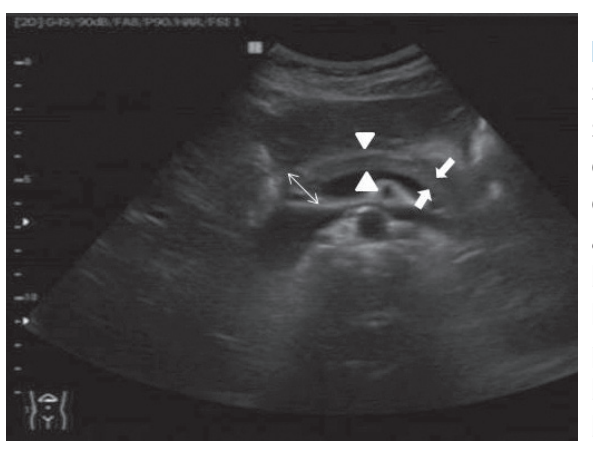

Figure 20. Normal size of pancreas. The size at head of pancreas is below 2.5 $\mathrm{cm}$ (arrow line) and at body (distance between arrowheads) and tail of pancreas (distance between arrows) is below $2 \mathrm{~mm}$.

\section{결 론}

췌장 초음파는 진료실에서 손쉽게 할 수 있고 방사선 피폭이 없어 임산부나 소아에서도 안전하게 검사할 수 있는 좋은 검사 법이지만 검사자의 숙련도에 따라 차이가 많고 췌장검사의 방해 인자가 많아 췌장을 초음파로 잘 관찰하는 것은 쉽지 않다. 하 지만 췌장 초음파 스캔 방법을 잘 알고 췌장 관찰에 방해되는 인자를 해결할 수 있는 방법들(압박법, 자세 변경, 음수법)을 잘 활용하면 췌장 관찰이 좀 더 용이할 것으로 사료된다. 하지만 이런 모든 방법을 동원해도 췌장이 안보이거나 선명하게 관찰되 지 않으면 판독할 때 이를 명시하고 필요하면 복부 전산화단층 촬영 등 다른 검사의 도움을 받아야 하겠다. 여기에 기술한 다 양한 췌장 스캔 방법과 방해인자의 해결책을 잘 활용하면 췌장 초음파검사에 많은 도움이 될 것으로 사료된다.

중심 단어: 췌장; 초음파; 가스 및 해결책; 제대로 검사하기

\section{REFERENCES}

1. Cosgrove DO, Meire HB, Dewbury KC, Farrant P. Abdominal and general ultrasound. 5th ed. New York: Churchill Livingstone, 1993:54.

2. Shim CS. Abdominal ultrasound. 3rd ed. Seoul: Ryo Moon Gak P. Co., 2007.

3. Lees WR. Pancreatic ultrasonography. Clin Gastroenterol 1984;13:763-789.

4. Choi BI. Upper abdominal ultrasound diagnosis. Seoul: Ilchokak, 1997.

5. Arger PH, Mulhern CB, Bonavita JA, Stauffer DM, Hale J. An analysis of pancreatic sonography in suspected pancreatic disease. J Clin Ultrasound 1971;7:91-97. 